Historic, Archive Document

Do not assume content reflects current scientific knowledge, policies, or practices. 

$6267 \quad$ INDEXED.

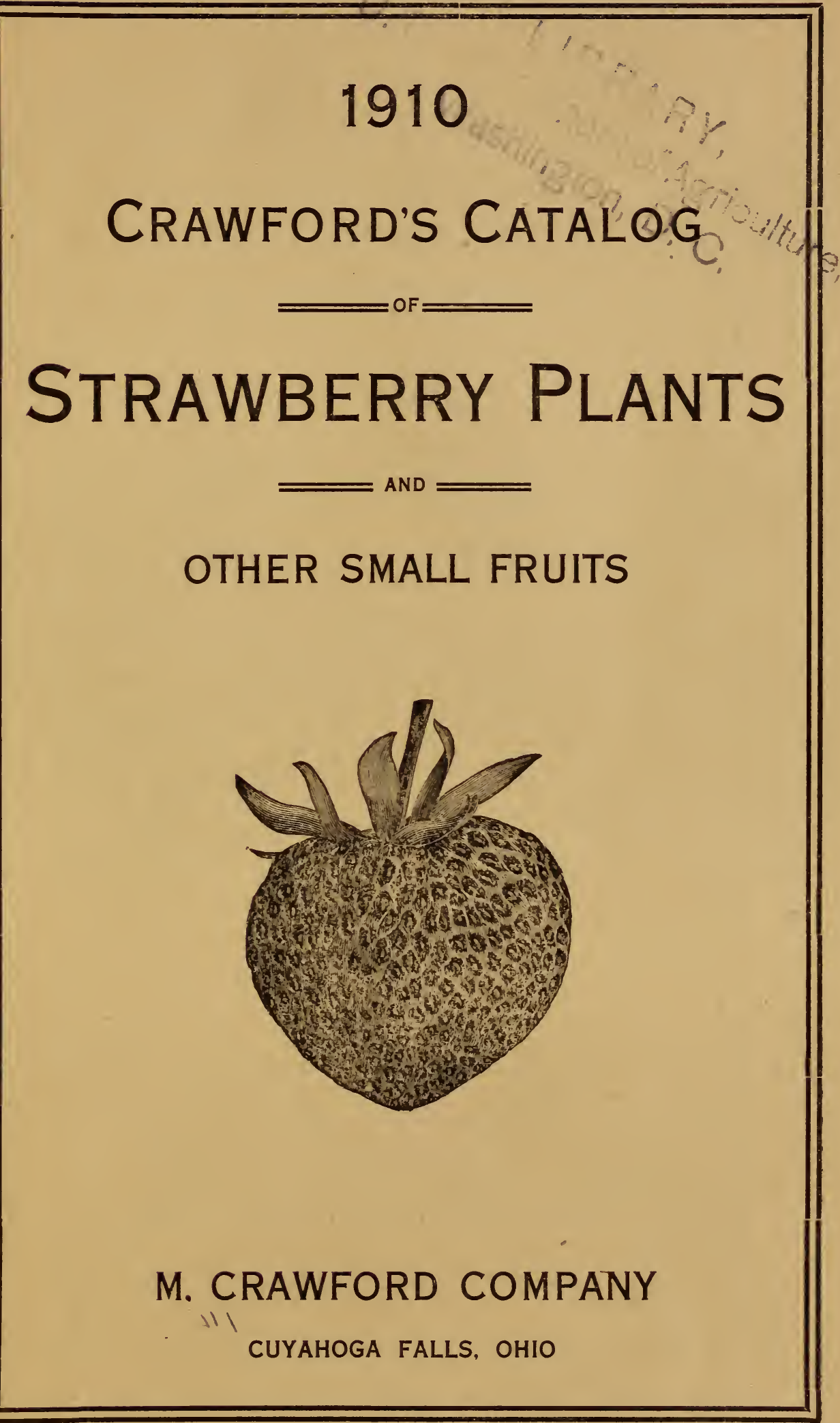




\section{GLADIOLUS BULBS.}

Our trade in bulbs is mostly wholesale, but for the accommodation of our plant customers we try to have a few to sell at retail every year.

Our XX stock is even finer than ever before. We believe that it is the best mixture in the country, and have received letters from good judges testifying that they hold the same opinion.

Blooming bulbs, by express, not prepaid, 20 cents per $12, \$ 1.00$ per 100 . By mail, 5 cents per 12 or 40 cents per 100 higher.

\section{CHOICE NAMED VARIETIES.}

America.-One of the most beautiful of all the gladiolus family. The flowers are large, and their arrangement on the stem is perfect. The color is a soft, delicate pink without markings. Very popular and desirable.

Early Amethyst.-This is a variation of the blue strain brought out a few years ago. Its color is a blending of violet and amethyst, and on the lower petal of each flower is a peculiar marking shaped like a spear head, yellow in color and contrasting finely with the blue and purple of the blossom. This variety grows very tall, and the stem is slender and graceful.

Gertrude.-A luxuriant grower, making a stem which is both tall and stout. The flowers are bright rose pink, with blotches of brilliant crimson or cherry in the throat. These markings appear on all the petals, making the blossoms very showy an $r$ t. tractive.

Princeps.-This splendid variety has been selling at high prices for several years, and shows no signs of becoming cheap, though we are offering it at a lower price than any other catalog we have seen. The flowers of Princeps are very large, especial$1 \mathrm{y}$ in width-in color the richest and most glowing red, and as lustrous as satin. In contrast with this the throat is pure white, making a beautiful and dazzling combination.

$\begin{array}{lll}\text { America - - - } 75 \text { cents per } 12 . \\ \text { Early Amethyst, } 50 \text { “ } & \text { “ } 12, \quad \$ 2.50 \text { per } 100 . \\ \text { Gertrude, - - } \$ 1.00 \text { “ } & \text { “ } 12, & 5.00 \text { per } 100 . \\ \text { Princeps, - - } 1.00 & \text { “ } & 12 .\end{array}$

\section{"THOROUGHBRED” PLANTS.}

As long as certain fallacies connected with our line of business continue to be promulgated as scientific truth, we must enter our protest whenever an opportunity offers. This time we have a few words to say about "thoroughbred" strawberry plants. The root of the word "thoroughbred" is "breed," of which "bred" is a derived form, and "thoroughbred" a compound derivative. "Breed" may be used in either of two senses, — "to procreate" or "to bring up." "Thoroughbred" applies to the former, and means "bred from the best," that is, produced by using the best as parents. This involves the laws of heredity, and it is along this line that the American Breeders' Association is working. Its efforts are directed to the improvement of plants and animals by selecting the best for seed or for procreative purposes, but growing strawberry plants from runners is an entirely different line of work, and there can be no comparison between the two. The plant which produces other plants by runners does not breed them, and is in no sense their mother. They are not its descendants, but are simply parts or extensions of the original plant, and possess exactly the same characteristics. These may be varied temporarily by environment,- by situation, soil, culture, food, moisture, and so on, but improvement in the size of plant or fruit, productiveness, or other desirable points, induced by better conditions and peculiar management, can not be "fixed," or made permanent. The variety is still the same, and will remain so as long as it exists. In view of the facts stated, we respectfully assert that "thoroughbred" is not a suitable adjective to apply to plants grown from other plants by runners, cuttings, buds or any other mode of increase that makes them merely parts or extensions of the original plants. There is only one way of obtaining a product which may correctly be termed "thoroughbred," and that is by the proper use of seed according to the laws of heredity. 


\section{NINETEEN HUNDRED AND TEN.}

The greetings of another year to our customers, and hearty thanks for past favors. May our future relations be as pleasant as those of former years have been. It is very gratifying to us to receive your orders season after season, and the good work you do for us by recommending us to your friends and so bringing us new customers is fully appreciated. To those who receive our catalog this spring for the first time we say that we should be glad to welcome you to our circle of patrons, and show you what service we can render. We should be most happy to have an order of some sort from every person who reçeives this catalog.

We send out good plants taken from beds set last spring, well cared for during the growing season, and protected with a covering of straw from the alternate freezing and thawing of winter and early spring. Our plantation is on ground that was never before used for strawberries. Last season was a good one for plant growth, and we have a much larger stock than in 1909 when the supply was short the country over, by reason of the notable drouth of the preceding autumn. White grubs were unusually prevalent in many localities last year, and we had them to contend with in some portions of our field. A few varieties suffered so severely that we have been obliged to omit them from our list this spring. Among them are Cardinal, Commonwealth, Marshall, Margaret and Norwood, besides several that we intended to offer for the first time. All the plants named in this catalog were grown on our grounds.

All orders received are acknowledged promptly,-within twenty-four hours as a rule. If you do not hear from us within a reasonable length of time please write again. So far as we know, there was but one order lost of all that were addressed to us last year.

Our packing is first-class, including plenty of moss for security, and yet made as light as possible to keep down trausportation charges. We receive many commendations on its excellence. We ship by mail and express with equal success. The express companies make a special rate on nursery stock, which is 20 per cent. lower than that on merchandise, but the minimum charge is 35 cents. For this reason it is better to have snall orders sent by mail, as the postage is only eight cents a pound. Our express companies are Adams and United States.

We warrant our plants to reach our customers in good condition. This practice was inaugurated by our Mr. M. Crawford when he issued his first catalog thirty years ago, and has been continued ever since. According to custom, we stipulate in this connection that while we are willing and anxious to make good any losses that may occur and to correct any mistakes, we shall not be liable for a sum greater than the original cost of the plants. Our warrant does not extend to Canada, the regulations of the Dominion in regard to the admission of nursery stock being such as to render it liable to delays which may involve loss.

We begin shipping about the first of April as a rule,--sometimes earlier, sometimes a little later, according to the season. We push the work as fast as possible, aiming to send out every order when it is wanted. It will be a great help to us in this matter if buyers will name the time of shipment when ordering, or if unable to do tis, say "Ship when notified," aud then write when ready.

We give good count, and our plants are carefully trimmed, tied in bunches, correctly labeled, and true to name. We receive many fine testimonials every year, and few complaints. Last season brought us three of the latter, and gave us opportunity to make good our promise of reparation, which we did to the best of our ability. We request that we be notified as promptly as possible when there is anything wrong. 
Our descriptions of the varieties that we have fruited are as accurate as we can make them, and we borrow from the best authorities on the others. Last spring the demand for plants so far exceeded the supply that we sold all we could possibly spare of the newer varieties, and planted the remainder, so we had none to fruit, and contrary to our regular custom we are obliged in some instances to quote our descriptions the second time.

Each year we make an effort to lessen the number of varieties on our list, and do drop some, but the old ones have so many merits and the new ones are so promising that our success falls short of our endeavors. Even the few that we leave out seem to have their special admirers who are disappointed that their favorites are omitted.

Every package of plants that we send out is accompanied by a certificate of inspection, and for every shipment by express a card of notification is sent by mail.

Our terms are cash with order or before shipment. We make exceptions to this rule in dealing with Experiment Stations and other public institutions. Remittances may be sent by post office or express money order, bank paper, or registered letter, or small sums in stamps.

We cannot commend too highly the wisdom of ordering early. Late in the fall we make an estimate of the number of plants of each variety in our field, and as orders come in we keep an account of the numbers sold. When the sales of any variety equal the estimate we mark it "sold out," and stop taking orders for it. It sometimes happens that a variety is in such demand that it is so!d out before we dig a plant. Thus it is easy to see that those who order early have the advantage.

Another thing to talk about is substitution. Early in the season when the stock is fuil there is no occasion to mention it, but later, as one kind after another becomes exhausted; we like to know whether or not we may send something else if the variety wanted is sold out. If those who order after the first of April would give us permission to substitute, or name a second choice for each kind wanted, it would be a great help to us and prevent the delay caused by correspondence. We reserve the right to substitute according to our best judgment after the middle of April, unless forbidden to do so.

\section{STRAWBERRY CULTURE IN A NUT SHELL.}

Make the soil rich.

Pulverize it thoroughly.

Plow early to conserve moisture.

Plant as early as possible.

Shorten the roots to three or four inches.

Do not allow the roots to be exposed to the air.

Set the plants so that the crowns will be even with the top of the ground.

Press the soil firmly about the roots.

Keep the surface stirred.

Cultivate after every rain and as many other times as are necessary to prevent the formation of a crust.

Give winter protection if your land and climate require it.

\section{CARE OF PLANTS WHEN RECEIVED.}

Plant at once if possible. If this can not be done, heel them in. Prepare a bed three or four feet wide and set the plants in rows across it, placing them an inch or two apart in the row, and making the rows four or five inches apart. Shorten the roots of the plants to three inches, and put them in water before setting. Begin at one end of the bed and work backwards. You will tramp on the prepared bed behind you as you work, but the soil can be easily loosened up again. When done scatter a little straw over the bed and the plants will be safe for a month, - until 
they have made a good growth of white roots. When wanted for planting they should be well watered the night before. They can then be carried to the field with some soil adhering. If they bloom in the temporary bed the blossoms should be nipped off.

\section{METHODS OF CULTURE.}

There are three popular methods of growing strawberries, - the matted row, the nedge row and hill culture. By the first the runners are allowed to grow without restriction; by the second each plant is permitted to set a limited number of new ones, and beyond these the runners are kept cut; by the third the runners are cut from the beginning, and never allowed to grow more than a few inches in length. The first costs the least work, and as a rule yields the most quarts of berries to a given space, but they are not the largest. The second involves more labor and produces larger fruit, but not quite as much to the acre. The third requires the most attention and gives the finest berries in return.

\section{DISTANCES IN PLANTING.}

Distances in planting vary according to the method of cultivation adopted, and the nature of the varieties used. As a general rule the rows may be three and onehalf feet apart. For the matted row, ordinary kinds may be set two feet apart, or a little more, in the row, and fast runners like Sen. Dunlap, four. If the plants are to be grown in hedge rows or by hill culture, a foot and a half is about right.

\section{SIZE OF PLANTS.}

Some varieties make very large plants, others medium, and still others small. Comparing Uncle Jim and Warfield, the plants of the latter might seem to an inexperienced buyer so small as to be worthless, but they are small by nature, not culls. They are tough and hardy, and will make many runners and bear large crops.

\section{NUMBER OF PLANTS TO THE ACRE.}

The number of plants required for an acre, set at any given distances, may be easily computed. One acre contains 43,560 square feet, and this number divided by the number of square feet occupied by one plant will give the number of plants to the acre. For instance: If the plants are to be set three and one-half by two feet, multiply these numbers together and the product is seven, the number of square feet required for each plant. Seven is cuntained in forty-three six times with a small remainder, hence, a few more than 6,000 plants will be needed. Again: Suppose the plan is three and one-half by one and one-half; multiply seven halves by three halves and the result is five and one fourth, which is contained in forty-three about eight times. Therefore the required number of plants is 8,000 .

\section{PERFECT AND IMPERFECT BLOSSOMS.}

Strawberry plants are divided into two general classes called perfect and imperfect, or staminate and pistillate. The perfect or staminate varieties have stamens, produce pollen, and fertilize not only their own blooms but those of the other class. The imperfect or pistillate sorts, as a rule, have no stamens and produce no pollen, hence their blooms must be fertilized by staminates. However, as a matter of fact, many of the so-called imperfect varieties have a few stamens and are able to pollenize themselves to some extent, but not sufficiently to produce a full crop. In planting imperfect or pistillate kinds every third, fourth, or fifth row should be set with some perfect or staminate variety. In our catalog we mark the perfect sorts $P$., and the imperfect I. 


\section{WHAT TO PLANT.}

This is an important question, especially to beginners in strawberry culture, and they sometimes find it difficult to choose among the many varieties described in cata. logs, and nearly all highly recomnended. The most of them are said to be large, and it is a fact that the great majority of the popular sorts are large. They are described as fine in color and gloss, and this also is true, for at the present day it is hardly considered worth while to bring out a berry that is not handsome. There is a somewhat wider range in the item of flavor, but still the beginner is bewildered. To such we would say, choose a few varieties that seem by their descriptions best suited to your requirements, and try them in a small way. You will be almost sure to find one or more that will be satisfactory, and that you will deem it advisable to plant more extensively. The information given in this book may be helpful to some extent, and if so we shall be glad, but our experience can not serve others as well as their own.

\section{OUR INTRODUCTIONS.}

This firm, as M. Crawford or M. Crawford Company, has introduced a large number of excellent varieties, many of which have become popular. Those described in this book are Brandywine, Empress, Gill, Helen Gould, Highland, Kittie Rice, Matthew Crawford, Miller, Mrs. Miller, Nick Ohmer, Senator Dunlap, Wm. Belt and Woolverton.

This year we are assisting, in connection with a number of other dealers, in the introduction of another new variety which promises to perform an important part in supplying the need of planters for good market sorts. We have already quite 2 number that possess great merit, but we believe there is room for another. We present this in the King Edward, and give it first place in our

\section{DESCRIPTIONS.}

\section{OUR ONE STRICTLY NEW VARIETY.}

King Edward. P.-Midseason. For several years past strawberry growers have been interested in this new berry and have looked forward with expectation to the time when it would be offered for sale. That time has now arrived, and we anticipate that those who buy will find in due time that they have obtained a prize. The originator, Mr. D. J. Miller, of Holmes County, Ohio, has been for many years an extensive fruit grower, and has taken a special interest in strawberries, growing many seedlings. He produced Miller and Mrs. Miller, both of which have proved excellent, and now offers us King Edward as his best. It it a seedling of the Miller, and was first named King, but afterwards changed to King Edward.

Mr. Miller adopted an original and rather novel plan for introducing his new berry, which will be likely to work to the mutual advantage of himself and the brying public. He sent out plants a year in advance to numerous dealers in order that they might raise their own stock and be ready for a general introduction with fresh plants grown on their own grounds. Furthermore, Mr. Miller has made the prices on King Edward so reasonable that all who want it in either small or large quantities can afford to have it. One dollar is a small sum to pay for a dozen plants of a choice new strawberry, and at twelve dollars a thousand planters can use it for their fields and be assured that it will pay, from the fact that it has been tried and has succeeded all over the country. Very few berries, if any, are given so general a test before their introduction. As we said, this is the only strictly new berry that we offer this spring, and we are pleased that it is so good and at the same time so moderate in cost.

We have fruited the King Edward several times, having had it on trial, and we value it highly. It is a vigorous grower, and a prolific yielder of large, handsome 
berries that are firm and good. For a more detailed description we quote from the report of the Ohio Experiment Station, which has justly earned the reputation of being conservative in its statements, believing that it will carry more weight than higher praise from less critical sources. From the Station report for 1906:

"King Edward.-Large, bluntly conical, very slightly necked, uniform; color bright, fresh crimson when fully matured, glossy and attractive. Flesh light in color, firm, fine grained, mild, sweet and good in flavor. Flowers perfect. First blossoms, May 7; full bloom, May 21; first ripe fruit, June 9; period of heaviest fruiting, June 15 to 23 ; largest single picking, June 18-three and one-half quarts; last picking, June 25; total yield for the season, eleven and one-half quarts. Plants large, vigorous, light green in color, making a beautiful fruiting row. A very promising variety originating in Holmes County, Ohio, where it is reported as having done exceedingly well again this season."

The foregoing test was made on a narrow row twenty-four feet long.

\section{OTHER VARIETIES.}

There are in the following list quite a number that we have not sold before; but as none of them are strictly new we do not place them in a division by themselves.

Abington. P.-Midseason. Found growing wild in eastern Massachusetts fifteen years ago by Lester Blancbard. A good variety in all respects. A thrifty grower with abundant foliage, and a good plant maker. The blossom is large and rich in pollen. The fruit is large, bright red, firm, and of excellent quality. It ripens with Bubach, and surpasses that old favorite in color, firmness and flavor. It is a generous yielder, and makes a long season.

Autumn. I.-Late. This is recommended as a fall-bearing variety. To make it a success as such, the spring fruit-buds should be removed, and the later crop of blossoms must be fertilized by some perfect-flowering sort which blooms at the same time. The plant is vigorous, but not large. The fruit is of fair size and fine shape, red, glossy, firm, and delightful in both fragrance and flavor.

Battenburg. P.-Late. From A. T. Goldsborough, of Washington, D. C. The plant is healthy and stocky, niaking numerous crowns which send up a succession of fruit stalks, thus giving the berry a long season and a heavy yield. The fruit is very large, and although rough and dull at first it improves as the season advances. The chief merits of this berry are productiveness, lateness, and great size. It has produced berries weighing from two to four ounces. The originator makes it emphatic that this variety must have narrow row culture and rich soil.

Blaine. P.-Midseason to late. This berry was introduced a few years ago, by J. W. Blaine, of Iowa, in a modest way without any loud praise, and seems to be making its way into favor on its own merits. It produces strong, healthy plants with rank foliage, a liberal number of runners, and large berries of fine color and flavor and very firm. The New York Experiment Station report says that it retains its size well throughout the season, and has a "marked desirable character."

Bountiful. P.-Medium, rather early. A seedling of Glen Mary, originated by J. E. Kuhns, of New Jersey. It is a candidate for popularity as a márket berry, and bids fair to make a success. It makes fine, large plants in ample numbers. We have not seen the fruit for reasons previously stated, but will give the report of the New York Experiment Station: "Fruit large to medium, retains size well in late pickings, roundish conic, medium dark scarlet, flesh well colored, firm, mildly acid, pleasant flavor, quality good. Above medium in productiveness."

Brandywine. P.-Late. One of the old favorites, especially in the south, and too well known to need many words. It is a cross between Glendale and Cumber- 
land, originated by E. T. Ingram, of Pennsylvania. Both plant and fruit are large, and the latter is fine in shape, color and flavor. Our stock is small.

Bubach. I.-Midseason, rather early. Originated by J. G. Bubach, of Princeton, I11., nearly thirty years ago. The vigor and productiveness of its plants and the astonishing size of its fruit made it popular at once, and it has held its own, notwithscanding the fact that it is not a good shipper.

Chesapeake. P.-Late. A Maryland berry, produced by John W. Parks. Seven years ago it won W. F. Allen's prize of $\$ 100$ offered for the best dozen plants of any unintroduced variety sent him. There were more than a hundred kinds in competition, and the Chesapeake won easily. The plants are rugged and healthy, with thick, substantial foliage. Not having fruited it we will borrow our description: "1t ripens about with Gandy, but is rather larger, and much more productive." The Ohio Experiment Station report says. "Large, conical; usually smooth and regular; color rich, dark crimson, glossy. Flesh pink or red, very firm, and of good quality."

Chipman. P.-Early. A native of Delaware, and much admired thereabout, vhere it has been grown as a market berry for several years. This is the first time we have offered it for sale, and we compile our description from the catalog of W. F. Allen: "The plants are strong, upright in growth, large and healthy, with glossy green foliage that has never shown any signs of rust or disease. The fruit is large, dark red, bright and glossy, and retains its bright color a long time after being picked. It is very firm and of good quality. Ripens four or five days earlier than Bubach."

Colossus, I.-Midseason. A seedling of Bubach, and much like its famous progenitor in both plant and fruit. Very productive, and the berries are enormous.

Columbia. I-Late in both blooming and ripening. Our description is arranged from that of Prof. O. M. Taylor, of the N. Y. Experiment Station. "Plants very numerous, strongly vigorous, healthy, very productive. Fruit large, often very large, wedge to roundish conic, attractive, glossy light scarlet. Seeds numerous, raised. Flesh well colored, firm, agreeably acid, good to very good in quality. Picks easily. Retains size well as season advances. One of the most promising kinds." On the Station grounds in 1907 it yielded at the rate of 10,000 quarts per acre.

Cooper. P.-Medium to late. Originated by Samuel Cooper, of Delavan, N.Y. A vigorous grower making plants freely and also a liberal yielder. Berries of medium size, about like Warield, conical, uniform, beautiful glossy red with yellow seeds. Flesh firm and of delicious flavor.

Dicky. P.-Medium to late. A Massachusetts berry, produced by J. D. Gowing. We repeat a former description. "The plants are very large, perfectly healthy, and wonderfully vigorous. It is said to be as productive as Sample, and to make a very long season. Berries roundish; color red; flesh red and firm; flavor rich and refreshing; calyx green and double; seeds on surface and skin not easily broken."

Early Ozark. P.-Early. From Charles Shull of Missouri, a cross between Aroma and Excelsior. This was in great demand last spring, and we sold all the plants we dared to part with, and were obliged to return many orders. We reserved a few plants for our own setting, and as we offer it only by the dozen this spring we hope to have enough to supply the demand. The plant is healthy, with full, dark green foliage, and exceedingly productive. Blossoms large, and rich in pollen; fruit firm, good, and of great size. Said to be "the largest extremely early berry ever introduced."

Ekey. P.-Early medium and makes a very short season. From E. H. Ekey of southeastern Ohio. This fine berry has been before the public four years, and has 
won its way from the first. It makes plants sparingly, but they are of extra size and yield well. The fruit is peculiarly attractive, very large, very long, and very dark red and glossy. The flesh is also dark red and solid. The flavor is pleasantly tart, sprightly and agreeable.

Empress. P.-Late. Originated by the late John Little of Ontario, Canada. The plant is healthy, a good grower and a bountiful yielder. The fruit is very large, conical, and sometimes corrugated. The color is dark red and glossy, and the quality is fine.

Fairfield. P.-Vcry early. A chance seedling from New Jersey. The plant is of medium size, tough and hardy, with long roots. The fruit is rather long, red with red flesh, and colors all over. It is firm, and of fair size and flavor. Although an early berry, it is late in blooming, which is an advantage in frosty localities. It makes a short season, which is also an advantage in a very early berry, for such varieties receive little attention after the larger ones begin to ripen.

Fendall. I.-Early. A seedling of Wm. Belt, produced by Chas. E. Fendall of Maryland. We owe our readers an apology for having described this variety as perfect flowering. We were not aware of our mistake until Mr. Fendall called our attention to it last spring after our catalog was distributed. This berry is remarkable for its immense plants with roots ten or twelve inches long, the splendid crops it yields, the extraordinary size of its fruit, its exquisite flavor, its rich, lustrous color, and the length of its bearing season,-from thirty to forty days. Although the plants are exceedingly productive they also make many runners which take root readily.

First Quality. P.-Late. From eastern Massachusetts. J. D. Gowing describes it as "a seedling of the Sample, and all that its name implies. A first-class handsome variety. Will bear double the berries that can be grown from Gandy or Brandywine." C. S. Pratt said in 1908: "It will surely take the place of the Marshall as a family berry. It will produce five times as much on the same space of ground. Great cropper, fine shape, and colors well. There is something about the flavor that completely captivates the taste, and it is a flavor that grows in favor." Mr. Pratt's cut shows a long berry resembling Haverland in form.

Fremont Williams. P.-Late. A cross between Gandy and Bush Cluster, from Louis Hubach, of Arkansas. Thrifty in plant and foliage and a free plant maker. This was introduced as a rival of its parent, the Gandy, and is likely to supersede that well known sort on account of its greater productiveness. It is the equal of the Gandy in size, shape, color and flavor, more prolific, and remarkable for its firmness.

Gandy. P.-Late. A native of New Jersey. For twenty years this has been the standard late berry. It is large, beautiful, good, and fragrant, but only moderately productive. It yields a better crop the second year than the first. Although classed as perfect flowering, some of its blossoms are pistillate.

Gill. P.- Very early. From southeastern Ohio, and highly recommended by the Ohio Experiment Station as the most productive of all the early sorts. It makes vigorous plants which send out many runners. The fruit is nearly round, of fair size and quality, and dark red when fully ripe. It is only moderately firm.

Glen Mary. P.-Early. The plants are large, have long roots, and yield prodigious crops. The berries are of marvelous size, bright red, firm and good, but inclined to be rough in appearance. The blossoms are rather weak in pollen. It is said to do best on a heavy, moist soil.

Golden Gate. P.-Early medium. Originated by S. H. Warren of Massachusetts, and sent out with high praise which has been verified by the behavior of the berry. It is a splendid grower, and the foliage is ample. The fruit is of great size, oval in form, shining red in color, and firm enough to make it a good shipper. The flavor is agreeable, though not rich. 
Goldsborough. P.-Second early. From A. T. Goldsborough, who has originated several varieties of high merit, and considers this as near perfection as he has been able to reach thus far. The plant is tall, with foliage that protects the blossoms and berries. The fruit is beautiful in form and color, and the red flesh is juicy, sweet and melting. Like the Gandy it bears both perfect and imperfect flowers.

Good Luck. P.-Late. Originated by Edward Pedrick of New Jersey. This, like Chesapeake, won W. F. Allen's hundred-dollar prize, one year later. He describes it as a very strong grower, and further says, "The fruit, compared with the Gandy is equally as large, more productive, and a few days earlier. In shape it is conical to wedge shape, with uniformly smooth, even surface, making it very showy, both on the vines and in the package."

Goree. P.-Early. An accidental seedling discovered by Mr. Goree of Texas. This is one of the varieties whose fruit we missed seeing last summer, much to our regret. "The vine is a strong, handsome grower and a good plant maker, enduring with impunity the hottest and driest weather. The foliage is of a dark, glossy green and perfectly healthy. The bloom is profuse, setting an enormous crop of berries which ripen out perfectly and are very firm, the best of shippers. The berries are from medium to large, heart-shaped, regular and uniform to an unusual degree, ripening all over, of a very rich, glossy, crimson scarlet, and shine as if varnished; seeds golden, prominent. Its quality is its crowning glory. It is exceedingly aromatic, and has in the highest degree the richest, sweetest, true wild strawberry flavor. Flesh solid crimson."

Gray's Dollar. P.-Medium. From A. G. Gray of Indiana. This is another of those varieties which we sold too short last spring. We repeat a portion of Mr. Gray's description: "A rank grower and a good plant maker; succeeds everywhere. The roots run deep and withstand both drought and freezing. Berries large, perfectly formed, pointed and glossy, bright rich red color, and the finest flavored, as well as the solidest, best shipper ever introduced. Each plant has from three to six fruit stems that stand up well for such an enormous load. It is the best pollenizer we have ever grown. Its foliage is light green and never shows any rust or spots.

Haverland. I.-Early. The mere name of this old favorite would sell plants by the ten thousand, and it is needless to occupy space in describing it. We have a fair stock of plants, but may wish it were larger before the season is over.

Helen Gould. I.-Medium to late. From J. R. Peck, of Missouri. After having fruited this berry several times we gave it out to the public three years ago, and it has been growing in favor ever since. It makes plants of a generous size, sends out a moderate number of runners, and is a plentiful yielder. The fruit is large, roundish conical, vivid, glossy red with red flesh, and moderately firm. Its flavor, though not the sweetest, is delicious. This variety should have an abundant supply of plant food.

Heritage. P.-Midseason. From New Jersey. This is rather new, and has not been generally disseminated yet, but in the east it is fast becoming popular. W. F. Allen says of it: "It is one of the healthiest and strongest growers that I have on the place." S. C. DeCou says: "The berry is unusually large and firm, with a shining color which is made the more attractive by its long green calyx. Of the many kinds I fruited last year (1908) this was in every way the most satisfactory. Large, handsome, productive, and of excellent quality."

Highland. I.-Midseason. A chance seedling found by T. B. Carlisle, of Mahoning County, Ohio. This grand berry was introduced by oûr firm two years ago. We sent it out recommended only by the very temperate reports of the Ohio Experiment Station, which is justly cautious about bestowing praise. As a result the 
Highland has exceeded the claims made for it, and has received warm commendation from skilled growers in various parts of the country. In growth it is a marvel of vigor; in productiveness it was the leader at the Experiment Station during the four years that it was on trial there, and it has maintained its record since its introduction. It surpasses its Station record in size and quality, and we believe in firmness also. In color it is all that can be desired. The flesh is red and very juicy, and the flavor though somewhat tart is sprightly and pleasing. For canning it is one of the very finest.

Island King.-Early. A seedling of Lovett, originated in Canada by Irvin Joyce and introduced last year by J. W. Thompson, who states that he had watched this berry in the hands of the originator for some time, and had tried repeatedly to obtain plants, but could not get one at any price until he bought the whole stock. He further says: "As a plant maker the past season (1908) it has nearly covered the ground at four by one and one-half feet. The berry ripens with Michel's Early, and is of good size, shape and color. A few of the first to ripen may show a little green tip, but after that they seem to color up well. The charm of the Island King seems to be its distinct, extraordinary flavor, whether on the table or taken from cans. Buyers, after they once purchased this berry passed everything else on the market, and paid an advanced price for Island King."

Jim Dumas. P.-Early. Originated by Louis Hubach, of Ark., and descended from Barton's Eclipse, Excelsior and Gandy. We offered this last year for the first time, and as in some other cases sold all that we could possibly spare, and then disappointed many, but we hope to supply them this spring. Mr. Hubach states that the Jim Dumas is a free plant maker and has very long roots and strong, healthy foliage. It is exceedingly productive, and holds out during a long season. The berries are very large and perfect, ripen nearly as early as Excelsior, and average twice as large. The flesh is red and of good flavor.

July. I.-Very late. Grown by H. J. Schild of Michigan, and genuinely late. On our grounds in 1908 it begun ripening sixteen days after Gill and Fairfield. The plant is of medium size, healthy, vigorous, and prolific. The berries, though not the largest are above medium in size, and among the most attractive in our collection, conical in shape, and as uniform as though cast in moulds. The color is perfect, brilliant red and glossy, and the flesh is juicy and delicious. Too delicate for long shipment.

Kittie Rice. I.-Midseason. Also called Downing's Bride. Originated and named by John F. Beaver of Dayton, Ohio. This is as fine as ever, productive, handsome and good, but we were unfortunate in the locality chosen for it last year, and have only a few thousand plants, hence we offer it in small numbers only.

Latest. I.-Late. Produced by S. H. Warren of Massachusetts. In 1904 the Ohio Experiment Station reported on this as "one of the most beautiful berries of the season, fully as late as the Gandy, and much better in quality." It makes a healthy, vigorous plant, and the fruit is extra large, and faultless in flavor, but only noderately firm. In shape it is long conical, and in color, a deep, brilliant cherry, with soft mottlings of lighter shades. It has one fault, it does not keep its fine color very long after being picked, but this does not seem to militate against its popularity.

Matthew Crawford. P.-Midseason. From J. R. Peck of Missouri. We clip the excellent description given in our last year's catalog: It makes a large, stocky plant, with dark green, healthy foliage, and is exceedingly prolific. The berries are conical, and very uniform in shape and size. The color is a brilliant red, growing darker when the fruit becomes very ripe. It colors all over at once. The flavor is fine, and it is very firm for so large a berry. 
Miller. P.-Early medium. Proủuced by D. J. Miller of Holmes County, Ohio, who is also the originator of King Fdward. Large plants, good runners, prolific yielders. Large, handsome berries, red, moderately firm, and of excellent quality.

Mrs. Miller. I.-Medium to very late. A companion to the Miller, and from the same grower. We have given a detailed description of this excellent berry five years in succession, and will pass it with few words this time. The plant is vigorous and productive. The fruit is remarkable for size, oblong in shape, of splendid color, and exceedingly firm. It ranks high in flavor.

Nettie. I.-Very late. From J. H. Black of New Jersey. In addition to its extreme lateness this is wonderfully productive, and the fruit is of extraordinary size, but poor in color and flavor, and unattractive in appearance.

Nick Ohmer. P.-Midseason. One of John F. Beaver's choice productions, and a fine berry for the amateur. With high culture the fruit is immensely large. It is exceedingly handsome, and the flavor is perfect. It needs winter protection, more than most varieties, as does also the Kittie Rice.

Orem. P.-Late. Originated by J. H. Arndt of Maryland. We sold this out clean last spring, and bought a fresh supply from Mr. Arndt for our own planting. We use his description again: "It is a vigorous grower, and has fine foliage to protect the beautiful berries from the hot sun. It comes in with the Gandy, and bears an abundance of fine berries even two weeks after the Gandys are gone. It bears about three times as many as the Gandy. The berries are exceedingly large and smooth, light red with yellow seeds and dark green calyx which makes them very attractive, and they ripen all over. They hold their size best of any I ever saw, and are good keepers. They can be left on the vines two days after they are ripe, and still be in first-class condition for market. The flavor is excellent."

Oswego. P.-Late. A New Yorker from L. J. Farmer, supposed to be a cross between Bubach and Sharpless. There are many berries of this type, with only slight differences, if any, among them. Corsican, Maximus, Uncle Jim, Wonder, and others belong to this class, and every strawberry grower is almost sure to be familiar with the grand plants and splendid fruit of one or another. They are all made on the generous plan, and yield large crops of luscious berries.

Outlander. P.-Medium. From Goldsborough. This is the variety that won the gold medal for the largest strawberries at the Jamestown Exposition. The originator says: "In the Haverland class as to type. The berries are of fine uniform size, and exceedingiy attractive in shape and color. They are oval with a neck and a handsome green calyx. Color bright red with darker hue where the sun strikes. Flavor only fair. Every blossom makes good."

Pride of Michigan. P.-Midseason. From O. A. D. Baldwin of Bridgman. This is another of the varieties on which we sold ourselves short last spring, so we have not seen the fruit, and will use Mr. Baldwin's description again: "Plant very vigorous and healthy, a good plant maker. Fruit stems strong, stand up well, and there are plenty of them. Productive. Size and shape about like Haverland, rather oblong. Color dark, glossy red. Shipping quality the best; very tough skin and firm berry. Plant is perfect and berry is perfect."

Red Bird. P.-Early. Originated in Mississippi, a cross between Murray and Hoffman. Said to be very early in the south, but with us it was a week behind Gill and Fairfield. The plant is a luxuriant grower. and the fruit is large, red to the center, juicy, and good, though not as sweet as many.

St. Louis. P.-Early. Known as Goldsborough's St. Louis. This berry is the result of crosses among several foreign varieties. The plants are only medium in size, but are healthy, and make runners freely. They are prolific, and should be 
pruned of part of their blossoms if extra large fruit is desired. The blossoms are large and the berries bright red. The quality is good. Mr. Goldsborough presented the Agricultural Department at Waskington a St. Louis berry which weighed four and three-fourths ounces.

Sample. I.-Late. This old veteran is from eastern Massachusetts, and so well known and popular that it hardly needs description. Its thick foliage, long roots, and unfailing crops of splendid fruit warrant its success as a money maker.

Saratoga. P.-Medium to late. Originated by Wm. Palmer of Saratoga County, N. Y. It is a cross between Glen Mary and Sample, and inherits their vigor and productiveness. The fruit resembles Sample in size, color and firmness. The flavor is good, but not remarkable for sweetness.

Sen. Dunlap. P.-Second early and makes a long season. Ten years ago our firm introduced this splendid berry, originated by J. R. Reasoner of Illinois, and long before the end of the decade it had taken first rank, both for market and home use. It makes rather small plants, but a great many of them, and they should be set much farther apart than most other kinds. They have very long roots and are as bardy as grass. They are enormously productive, and the berries are of good size when the plants have plenty of room, which is a necessity with varieties of this class. The fruit is uniformly conical in shape, intensely red in color, superb in flavor and firm enough to bear shipping hundreds of miles without losing its brightness. It succeeds everywhere.

Stevens' Late Champion. P.-Late. This variety makes healthy, robust plants which produce plenty of runners and liberal crops of fruit. The berries are large, long, and firm. The flesh is light red, and of fair quality. It is an excellent keeper.

Superior. P.-Early medium. From Delaware. Not a new berry, but this is the first time we have offered it, and we borrow our description from some eastern growers. W. F. Allen says: "The plants are strong, healthy growers, and succeed on almost any soil. It is a great plant maker and should be planted a good distance apart. It sets an immense load of fruit which is medium in size, bright glossy red, firm, and a good keeper." E. W. Townsend \& Co. speak highly of its productiveness, flavor and shipping qualities.

Taft, from Goldsborough. I.-Second early and makes a long season, It is the originator's favorite among all his fine varieties, and as we missed seeing it fruit last season we give his opinion of it: "Its foliage and roots are extra healthy, and it makes just the right number of good strong runners. Bloom and fruit protected by large round leaves. Fruit round and regular, color dark red, flesh same. Its prominent yellow seeds are well spaced. Fragrant and juicy. Favor sweet and rich. If you have a taste for a sweet, true, strawberry flavor, grow the Taft. No sweeter than Goldsborough, but one-third larger."

Uncle Jim or Dornan. P.-Late. Originated in Michigan by J. F. Dornan, from whose name it obtained both of those by which it is known. One of that large class of grand berries which resemble each other so much that one description with slight variations would answer for all. They all make immense plants, and roots that are a wonder for length and abundance, and all yield great crops of great berries which hold their size well. The fruit is bright red and firm, with light red flesh. The quality is good.

Warfield. I.-Second early. Discovered in 1883 by B. C. Warfield of southern Illinois. This and Sen. Dunlap are similar in some respects. Both make small, hardy plants with long roots, which enable them to resist drouth, and perfect large crops of fruit. Both are rampant runners, and should have plenty of room. Both produce handsome conical berries of lustrous red, and both are first-class shippers. 
The Warfield being pistillate requires a pollenizer, and the Dunlap is the very best for this purpose.

Wm. Belt. P.-Midseason. A native of southern Ohio, and named for its originator, now deceased. For fourteen years this has been before the public, and almost from the first it took rank as the best of all in flavor. It is also superior in beauty, size, and productiveness. The color is bright red. The first berry to ripen on each stem is cockscombed, but the others are conical. The plant is grand, and the foliage abundant and healthy. There was a time when it was subject to rust in some localities, but we have heard nothing of it lately.

Wonder. P.-Late. Produced by S. A. Sampsel of Sandusky County, Ohio. It is of the same type as Armstrong, Corsican, Uncle Jim and others, - - giant in plant and fruit, red and juicy and every way desirable.

Woolverton. P.-Medium to very late. Originated by the late John Little of Canada. Introduced by M. Crawford in 1891, and we give a few sentences from his catalog of that date: The Woolverton is a luxuriant grower, remaining green and healthy all summer, sending out a good number of runners and bearing abundantly. It continues in bloom a long time. The fruit is very large, and resembles Bubach, except that the first and largest berry on the stem is often more irregular. The color is a brilliant red and the quality is good.

Wooster. P.-Midseason. Discovered on the farm of E. W. Wooster, in Maine, in 1904. Supposed to be a seedling of Clyde and Sample. Mr. Wooster observed that the plants were tall and upright with long fruit stems which were borne to the ground with their load of fine fruit. The berries resembled Sample in form and color, but were more like Clyde in the way the seeds were set. It surpassed both in flavor.

\section{EVERBEARING STRAWBERRIES.}

Our last year's catalog made mention of these, and assuming that our readers will want to hear more, we gladly give another season's experience. We wish to make it plain that these new berries are not of the class called "fall bearing," but as their general name implies they yield fruit all through the summer and autumn, and freeze up loaded with berries at last.

Mr. H. Rockhill, of Iowa, is the originator of this new marvel in strawberries, and it took him about twelve years to attain the end for which he was laboring. We stated a year ago that we expected to grow plants for Mr. Rockhill last season to supply the trade this spring, and that arrangement was carried out. He sent us plants of ten varieties last spring. The ground was too wet for planting when they came, and they were heeled in and left in this temporary bed until they were in full bloom. After cutting off the blossoms the plants were set out in rows three and one-half feet apart, and eighteen inches apart in the row. The soil was a clayey loam of moderate fertility. A few plants of each variety were allowed to bear all they would, but the main bed was differently treated. Its blossoms were cut four times in June and July. A moderate amount of a complete fertilizer was applied, and it was cultivated and hoed the same as our other beds.

Now, as to behavior: The plants from which the blossoms were not cut fruited continuously from June until the latter part of November, and were a wonder in growth and yiald, even surpassing those that we had tested the previous year, and on which we reported in last season's catalog.

Early in August the main bed came into bloom for the sixth time, and the rows were white, as they are in May. From that date the fruit was allowed to ripen. The most of the plants had been making runners all summer. About the first of September the berries commenced to ripen, and the bed continued in bearing for 
nearly three months. We had our last strawberry shortcake on the twenty-first of November, and there were still bushels of green berries on the plants when the ground froze up for winter a day or two later.

The plants that fruited all summer and fall in 1908 commenced again last year, and appeared to be about as full of fruit as the newer bed. They bore all summer and fall again, but were left to themselves to see what they would do, and neither hoed nor weeded, consequently the berries were not as fine as the year before.

In regard to productiveness: Of course the everbearing varieties do not carry at one time any such loads of fruit as the June ripening sorts, but seven of the ten sent us are good yielders, and there is always a coming crop in sight. They never stop work, and their fruit brings extra prices. Two of the best have been named Francis and Americus, and Mr. Rockhill intends to introduce these first. There is one which bears more than either of these, but it makes so few runners that it will be a long time before a good stock can be worked up.

In size, there was a time when these berries would have been called very large, but standards have changed since then, and we might now say medium. Many of them were over an inch in diameter, and a few reached an inch and a half. We have not seen them at their best yet, for in 1908, the first year that we grew them, we had the most remarkable drouth of this generation, and in 1909, September and October, the main fruiting time of our large bed, although not as trying as the previous year, were too dry to do strawberries justice.

As soon as we had berries to sell, in September, we telephoned to a first-class grocer in Akron, our county seat, and he agreed without seeing them to pay forty cents a quart, which he did for all that we could furnish throughout the season. When picking for market the berries were sorted, and about one-fourth by measure were left out as too small. A few baskets of the salable berries were counted and ran from fifty to sixty to the quart. Our baskets are full quarts, and were well heaped.

As to flavor, all the varieties fruited on our grounds, with one exception, are exceedingly rich and delicious. Many people came to see them in bearing, and were surprised and delighted, not only with the wonderful show of fruit, but with its superior flavor as well. The berries were exhibited at the September and October meetings of our county horticultural society which is attended by from one hundred to one hundred and fifty people, and at our county fair in October, and were tasted by many. It was the universal opinion that they were sweeter and richer than the June bearing varieties.

In keeping and shipping qualities they are equal to the best.

Mr. Rockhill's berries are all good growers and runners, and the foliage is remarkably healthy. We do not remember ever having seen a rusty leaf on one.

Mr. Rockhill owns every plant in existence of these everbearing varieties, and not one can be obtained from any source until he is ready for their introduction. Our customers will be informed when they are put on the market.

\section{CERTIFICATE OF NURSERY INSPECTION.}

No. 246.

Columbus, Ohio, August 24, 1909.

This is to certify that in accordance with the provisions of the Nursery and Orchard Inspection Law of the State of Ohio, the nursery stock for sale by M. Crawford Company, of Cuyahoga Falls, County of Summit, State of Ohio, has been inspected by a duly authorized Inspector, and has been found apparently free from dangerously injurious insects and plant diseases.

Invalid after September 15, 1910.

N. E. SHAw, Chief Inspector. 


\section{PRICE LIST OF STRAWBERRIES. PLEASE PRESERVE A MEMORANDUM OF YOUR ORDER HERE.}

Date I9IO

Amount sent, $\$$

To be shipped by

on or about

These prices are by express, not prepaid.

When plants are ordered by mail, add 5 cents for each dozen; 10 cents for each 25; 30 cents for each 100 .

For Canadian orders the above rates must be doubled.

Six plants of one variety at dozen rates; 50 plants of one variety at hundred rates; 500 plants of one variety at thousand rates.

Customers sometimes want 100 plants made up of four 25 's, or 1000 made up of four 250 's, and do not know what price to affix. For this reason we have placed the prices of 25's and 250's in our list.

Imperfect varieties (I) must have perfect varieties (P) near them.

Imperfect and pistillate mean the same; perfect, staminate and bisexual mean the same.

\begin{tabular}{|c|c|c|c|c|c|c|c|c|c|c|c|}
\hline & 12 & $|25|$ & $|100|$ & $|250|$ & 1000 & & 12 & 25 & 100 & 250 & 1000 \\
\hline & .20 & .30 & & & &.$I$ & .20 & .30 & & & 5.0 \\
\hline & .20 & .30 & & & & $\ldots P$ & .50 & .75 & 2.50 & & \\
\hline & .50 & & & & & Jim Dur & .20 & .30 & 10 & & \\
\hline & .20 & .30 & .75 & & & July. & .20 & .30 & & & 4.00 \\
\hline & .50 & .75 & 2.50 & 4. & & $\mathrm{Kin}$ & 1.00 & 1.25 & 3.00 & & \\
\hline & .20 & 30 & .75 & & & Kit & .20 & .30 & .75 & & \\
\hline & {$[.20$} & .30 & .75 & 1. & 4.00 & Lat & .20 & .30 & .75 & & .00 \\
\hline & .20 & .30 & .75 & & & & .20 & .30 & .75 & & 500 \\
\hline & .20 & .30 & .70 & & &.$P$ & .20 & .30 & .75 & & \\
\hline & {$[.20$} & .30 & .75 & & & $\ldots I$ & .20 & .30 & .75 & & \\
\hline & {$[.50$} & & 2.50 & & & & .20 & .30 & .75 & & \\
\hline & .20 & .30 & .75 & & &.. $\mathrm{P}$ & .20 & .30 & .75 & & \\
\hline & .20 & .30 & .75 & & & & .20 & .30 & & & \\
\hline $\mathrm{P}$ & .50 & & & & &..$P$ & .20 & .30 & .75 & & \\
\hline & .20 & .30 & .75 & 1 & 5 & & .50 & .75 & 2.50 & & \\
\hline & .20 & .30 & .75 & & & Iich & .20 & .30 & .75 & & 5.0 \\
\hline & .20 & 30 & .75 & & &.. $\mathrm{P}$ & .20 & .30 & .75 & & \\
\hline & {$[.50$} & .75 & 2.50 & & & & .50 & .75 & 2.50 & & \\
\hline & & .45 & 1.0 & & & ... I & .20 & .30 & .75 & & .00 \\
\hline & .20 & .30 & .7 & & & & .20 & .30 & .75. & & 00 \\
\hline & .20 & .30 & .75 & & &. $\mathrm{P}$ & .20 & .30 & .75 & & 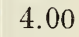 \\
\hline & .20 & .30 & .75 & 1.35 & & & .20 & .30 & .75 & 1.35 & 4.0 \\
\hline & .20 & .30 & .75 & 1.3 & & & .20 & .30 & & & \\
\hline & .20 & .3 & .75 & & & & 1.00 & & 5.00 & & \\
\hline & .20 & .30 & .75 & 1.35 & 4.0 &.. $\mathrm{P}$ & .20 & .30 & & 1.35 & 4.0 \\
\hline & & & .75 & & & & .20 & .30 & 75 & & \\
\hline & .50 & & 2.50 & 4. & & & .20 & .30 & & 1.35 & $4 .($. \\
\hline & & ? & .75 & & & & .20 & .30 & .75 & 1.35 & 4.0 \\
\hline & & .3 & .7 & & & & .20 & .30 & .75 & & \\
\hline & . & .30 & .75 & & 5.00 & Wooster.............P & .30 & .45 & 1.00 & 1.75 & 6.00 \\
\hline & & & & & & & & & & & \\
\hline
\end{tabular}

\section{CLASSES AS TO TIME OF RIPENING.}

FOR CONVENIENCE WE GIVE ALPHABETICAL. LISTS OF THE EARLY, MEDIUM AND LATE VARIETIES.

Early.-Chipman, Early Ozark, Fairfield, Fendall, Gill, Glen Mary, Golden Gate, Goldsborough, Goree, Haverland, Island King, Jim Dumas, Red Bird, St. Louis, Sen. Dunlap, Taft, Warfield.

Midseason.-Abington, Blaine, Bountiful, Bubach, Colossus, Cooper, Dicky, Ekey, Gray's Dollar, Helen Gould, Heritage, Highland, King Edward, Kittie Rice, 
Matthew Crawford, Miller, Mrs. Miller, Nick Ohmer, Outlander, Pride of Michigan, Saratoga, Superior, Wm. Belt, Woolverton, Wooster.

Late.-Autumn, Battenburg, Brandywine, Chesapeake, Columbia, Empress, First Quality, Fremont Williams, Gandy, Good Luck, July, Latest, Nettie, Orem, Oswego, Sample, Stevens, Uncle Jim, Wonder.

\section{RASPBERRIES.}

We have planned for some time past to add raspberries to our stock, and with that end in view we bought plants of one fine red variety and three blackcaps. The red will not be ready to sell till next fall. Of the blackcaps the plants of one kind were dead when received, and could not be replaced until the next year, and another did not multiply rapidly enough to make sufficient plants, but of the third we have a fine stock. This is the

Plum Farmer.-It was introduced by L. J. Farmer of New York, and bas been in the market some six years. It has given great satisfaction, and growers are enthusiastic over it. In vigor and productiveness it is unsurpassed. It is quite early in ripening, and matures its entire crop in a short time. 1t is of large size, and fully up to the standard in quality and appearance. $50 \mathrm{cts}$. per $12 ; \$ 2.00$ per $100 ; \$ 15.00$ per 1000 .

\section{BLACKBERRIES.}

The Watt.-As promised a year ago, we are now ready to offer this fine blackberry to our customers. We have never been in the habit of overpraising varieties that we had for sale, and least of all is it necessary in this case. The simple truth is sufficient. We have fruited the Watt three years, but have been familiar with it much longer. It was found growing wild in an orchard near Lawrence, Kansas, by Mr. D. G. Watt, whose name it bears. It was so large and productive and of such fine quality that Mr. Watt took it up and planted it where it could have a fair chance. It made a good record, and a neighbor of MIr. Watt's called our attention to it as a variety of great promise. While growing on Mr. Watt's place it endured a temperature of thirty degrees below zero without injury.

After making the acquaintance of the Watt by report we received a few plants from the owner for testing, and also a glass jar of the fruit, which was so fine in both looks and taste that it greatly enhanced the value of the variety in our estimation. Four years ago we made arrangements with Mr. Watt to have a portion of the stock put into our hands to be propagated and introduced, and we now offer it with confidence, fully expecting that it will occupy a prominent place among the leading varieties. We do not warrant it to be proof against the diseases and enemies of the blackberry, but we believe that it will resist their attacks as well as any, and better than some.

The plant is an excellent grower, much better than the Eldorado which was beside it, and fully equal to the Blowers which came next. The wood of the Watt is of very firm texture, and so tough that the branches rarely if ever split down with their load of fruit. In fact its habits of growth and productiveness are such as to commend it to all who cultivate blackberries.

Its period of ripening extends over a very long season, beginning soon after the earliest, and continuing till October. Our last picking for market last year was on the twenty-fifth of September, but there were berries after October first. The Blowers yielded some berries as late but they were not as fine. The fruit is all that could be reasonably expected, large, jet black, glossy and attractive, and the quality is excellent.

Prices: $\$ 1.00$ per $12 ; \$ 5.00$ per $100 ; \$ 40.00$ per 1000 . If wanted by mail add 10 cts. per 12 . Root cuttings by mail 30 cents per $25 ; \$ 1.00$ per 100 . Fifty at hundred rates, 
of either plants or cuttiugs. Special rates will be made on sucker plants, to be grown for fruit only.

Blowers.-Well known. From western New York. A sturdy grower and a very prolific bearer. The fruit is large and continues to ripen through a long season. The plant is hardy in its native region, and has endured quite a low degree of temperature unharmed. We begun selling the Blowers in 1904, and have sent it all over the country. We have received only one report of its having been winter killed, so far as we can remember, and that was from northern Minnesota.

Eldorado.-A general favorite. The best known of all blackberries the country over, and perfectly reliable in every way. It is a good grower, and hardy everywhere. The berries are of good size, glossy black, and very sweet and tender. They retain their luster a long time after being picked. This variety was discovered by E. M. Buechley of south-western Ohio many years ago.

Ward.-A native of New Jersey, found in a fence row. A thrifty grower making rather short canes with healthy foliage. The fruit is large, equal to the Blowers, and both are generally described as very large. The color is jet black, the flesh melting, and the quality very fine.

Prices-Blowers, Eldorado, Ward :

No. 1 plants, 40 cts. per $12 ; \$ 2.00$ per 100 :

No. 2 " 25 " " $12 ; \$ 1.50$ " 100 ;

If wanted by mail add 10 cents for each dozen.

\section{CURRANTS.}

Comet.-This it a native of the island of Jersey. We have had it in bearing eight years, and it ranks high in our estimation. It is a vigorous grower with bealthy foliage which stays on late. It is a prolific yielder, and both bunches and berries are large. It is rich red in color, of excellent flavor, and makes a long season.

Perfection.-A cross between Fay's Prolific and White Grape, originated by C. G. Hooker of Rochester, N. Y. It is the best American currant, and received the fifty-dollar Barry gold medal of the Western New York Horticultural Society, and the liighest award at the Buffalo Exposition; also, a gold medal at the World's Fair in St. Louis.

It is a splendid grower, making large, strong plants which produce wonderful crops of large, bright red fruit in very long clusters. The flavor is nild and agreeable making it fine for table use. It is easy to pick, having a long stem between fruit and branch.

Prices-Comet, Perfection:

No. 1,15 cts. each; $\$ 1.25$ per $12 ; \$ 8.00$ per 100 .

No. 2.10 “ “ $\quad .80$ “ $12 ; 5.00$ “ 100 .

"The strawberry plants arrived in due season,-fine plants, packed in your usual first-class style. In my whole experience with your firm, probably in over a dozen different seasons, covering nearly twenty-five years, I have never got a bad lot of plants, nor any that were poorly packed, or that proved untrue to name. It seems to me that this ranks about as close to 100 per cent. in the scale of fair dealing and general excellence as one can hope to meet in a finite world."

T. C. Robinson, Owen Sound, Ont.

"We are very well pleased with the strawberry plants. We have not lost one out of the lot of 1,200 . They were heeled in and planted when we could get the ground ready, and now they are doing very nicely, in fact better than any we ever planted."

C. BETSCHER, Canal Dover, Ohio. 


\section{A FERTILIZER FOR THE STRAWBERRY.}

It is absolutely necessary to have a fertilizer for the strawberry in order to make its cultivation profitable, and in many localities the commercial article is the only kind obtainable. This being the case, growers are interested in finding out what is the best kind, where it can be bought, and the price. Our Mr. M. Crawford has used conmercial fertilizers for many years, has tried many brands, and made many experiments. As a result of his observations he recommends a Potato Phosphate manufactured in Zanesville, Ohio, and sold at thirty dollars a ton. It is honestly made, of good materials and produces wonderful results. It is packed in sacks weighing 100 pcunds each; price $\$ 1.50$ per sack. The buyer pays the freight. Ask your agent the rate from Zanesville, Ohio. Send your order to us with the cash and the goods will be shipped promptly. The ammonia contained in this brand is in an available form, and not locked up in worthless materials, such as ground leather scraps, hair, and so on. We give below the guaranteed analysis:

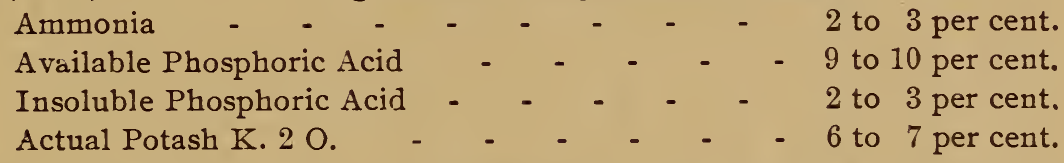

We have been selling this fertilizer through our catalog for four years, and so far as we have heard, it has produced good results and given excellent satisfaction. During the first year we received many inquiries as to the best way of applying it, and since then we have given brief directions for its use, which we again repeat:

For strawberries, one way is to put it in with a grain drill, after the ground is prepared for planting, about a week or ten days before the plants are to be set, thus giving it time to become somewhat blended with the soil. By this method the entire surface is enriched, and for growing fruit in wide matted rows it has the advantage of giving all the plants an equal chance.

Another way is to wait a short time after the plants are set, until they have started into growth, and then apply the fertilizer by hand, strewing a small quantity around each plant. Care must be taken not to let it touch the leaves, as it is liable to burn them. For this reason it should be put on when the air is still, and also because a wind, or even a gentle breeze, carries away the fine dust, and thus a portion of the richness is lost. When applied in this way the amount used may be divided, and part put on in the spring, say two-thirds, and the remainder in September, thus giving the runner plants a share. The amount required is exceedingly variable, according to the previous fertility of the soil, and the results aimed at. From 400 to 1000 pounds per acre may be used, and even more, if desired.

It has been our custom to use about 600 pounds to the acre for growing plants, but last spring our strawberries were set on land of only moderate fertility, and we increased the amount to 800 pounds.

"I received the plants in excellent condition, considering the long distance they have traveled. They are very good plants, and I am much obliged to you for sending them so early. I shall be pleased to recommend your firm to my friends."

HERBERT C. REDKNAP, Victoria, B. C.

"The plants were very fine and received in splendid condition, with the result that I did not lose a single plant. Thanking you for your generous treatment, I remain,

W. S. ToDD, Greenwood, Del.

- "I have never found any place where I could buy finer plants, and no descriptions of plants and berries that are so thoroughly reliable as yours."

W. A. RUSSEL, K, Kokomo, Ind.

"Plants came in fine shape and just as ordered. You give good count."

Lours Hubach, Judsonia, Ark. 


\section{ILLUSTRATED CATALOGS.}

We are sometimes asked why we do not use pictures of fruits in our catalogs, and this seems to be a good opportunity to state our reasons for not doing so.

We have issued a plain catalog for many years, and it has served our purpose well. We are plain people, and our statements are conservative. If we were to use illustrations it would be contrary to our principles to exaggerate in them any more than in descriptions. We should require that every picture be the exact size of the fruit from which it was made, and such pictures would as a general thing be so modest in size that they would hardly be noticed in comparison with the misrepresentations extant. We receive many illustrated catalogs, and some of them keep to the truth, but others exhibit fruits and various kindred products which are monstrous in dimensions. They are said to be photographed from nature, and no doubt they are, but they are so magnified as to be out of all possibility of truthfulness.

Take the strawberry for instance: All who are familiar with this fruit know that its seeds are small. What then is the conclusion when they appear in a picture as large as radish seeds, or even larger? W' $\in$ have often seen them one-sixteenth of an inch in length, by measure. We assert without hesitation that all such pictures are frauds. The Fendall, a new strawberry of great size, is pictured in various catalogs this spring, and although the illustration is nearly three inches across, it is an exact reproduction of the berry, as may be seen by its small seeds; but what shall we say of those others with seeds four times too large and set a quarter of an inch apart in the berry? We repeat that they are frauds, and compared with them, correct pictures of most varieties would appear at a great disadvantage as to size.

Another point worth noting is the fact that the same cut or halftone is often made to do duty for several different varieties. This practice, like that of exaggeration, militates seriously against the reliability of pictures. We have in mind a catalog received this spring which illustrates a certain berry with a picture of a cluster, and a few pages farther along a portion of the same cluster is used to represent another berry, every item of this being identical with the first, as far as it goes.

We do not say that we shall never issue an illustrated catalog, for we can not predict what inducements may appeal to us in the future, but we assert positively that if we ever adopt the use of pictures, they will be exact in size and true to name.

"Strawberry plants came same old way. Fine plants, fresh, well trimmed, well packed, extra good count. Heeled in, all growing. Thank you for the nice plants received in so fine condition." J. M. RAMALEY, Greensburg, Pa.

"The plants arrived some days ago in fine order. Many thanks for promptness and liberal count."

M. J. Graham, Adel, Iowa.

"I wish to acknowledge for the Station the receipt of package containing four varieties of strawberries which arrived in excellent condition."

O. M. TAYLOR, Experiment Station, Geneva, N. Y .

"The plants were fine ones, as yours always are, and excellently packed. I thank you very much for your generosity." MRS. HARRY ELLIOTT, Sycamore, Ill.

"Strawberry plants arrived in good coudition. Many thanks to you for good plants, good count, and good packing."

A. W. BAcon, Albion, N. Y.

"The strawberry plants you sent me were as fine a lot and well rooted as I ever purchased."

JOHN A. MOSHER, Wellington, $\mathrm{O}$.

"I meant to acknowledge before this the receipt of the plants you sent me, and to express my more than satisfaction with both quantity and quality. Better plants or plants in better condition I have never seen. Thank you for your extremely liberal treatment, and be assured I will speak a good word for the M. Crawford Company."

ARTHUR SMITH, Johnson, Ark.

"Yours to hand, also plants in most excellent shape. Thanks for promptness and fine stock."

A. G. GRAY, Pekin, Ind. 